\title{
NGOs' Social Capital Development Initiatives for Social Welfare: Bangladesh Experience
}

\author{
M. Rezaul Islam ${ }^{1,2}$
}

Published online: 6 August 2015

(C) Springer International Publishing 2015

\begin{abstract}
This paper presented two non-governmental organizations' (NGOs') social capital development initiatives for social welfare in Bangladesh. This study was based on a qualitative case study approach using a multi-method data collection procedure, where a semi-structured interview, social mapping, participant observation, in-depth case study, focus group discussion (FGD), and documentation survey were employed. The study selected two NGOs such as Proshika and Practical Action Bangladesh (PAB) working with two indigenous communities, e.g. blacksmiths and goldsmiths. This paper considered the application of the main elements of social capital such as collective actions, social trust, coordination and cooperation of mutual benefits, and sharing norms and values. The findings showed that in many cases, NGOs' social capital development initiatives for social welfare were successful. The findings would be useful for the social workers, policy makers, development practitioners, and NGO managers.
\end{abstract}

Keywords NGOs $\cdot$ Social capital $\cdot$ Social welfare $\cdot$ Bangladesh

Declaration I am declaring that the article is original and that it has not been submitted for consideration of publication elsewhere.

M. Rezaul Islam

rezauldu@gmail.com

1 Institute of Social Welfare \& Research, University of Dhaka, Dhaka, Bangladesh

2 Department of Social Administration and Justice, Faculty of Arts and Social Sciences Building, University of Malaya, 50603 Kuala Lumpur, Malaysia

\section{Introduction}

Non-governmental organization (NGO), social capital, and social welfare are three distinct but closely associated terms. In the recent time, NGOs' development initiatives in social capital development in the developing countries like Bangladesh give an important space in social welfare. Now, social welfare is a matter of right rather than of need. Kwok (2003) mentioned that social welfare is one of the systems of transfer payments to bridge the gap between the poor and the rich. In many developing countries such as Bangladesh, NGOs' development practice has been widened largely to respond to the needs of the disadvantaged people because of the lack of government support (Islam and Morgan 2012a; Devine 2006; Islam 2014a, b). NGOs' contribution in social welfare has been popular in many ways, such as 'democratisation of development' (Clark 1991), 'sources of development alternatives' (Drabek 1987), 'innovative approach' (Newaz 2003), 'vehicle for popular participation' (Farrington and Bebbington 1993), 'advocates for the poor' (Newaz 2003), and 'cost effective and efficient' (Bebbington 2004).

Social capital describes the pattern and intensity of networks among people and the shared values which arise from those networks. The main stance of social capital used in this paper is to build a greater interaction between people generating a greater sense of community spirit. A number of authors such as Islam and Morgan (2012a, b), Abom (2004), and Islam (2014a, b) argued that NGOs' contributions in social capital development helped to develop social network, social trust, and community empowerment among the vulnerable people. In a recent paper, Islam (2015) explained how Bangladeshi NGOs' are helping in different aspects in community development such as improving participation, social networking, partnership, and development ownership. NGOs 
have become increasingly involved in providing health care, education, and services to people; they have also become critical in ensuring social welfare (Jianxiu 2006). This paper showed NGOs' social capital development contributions towards social welfare in a general and broader term. The main objective of this paper is to evaluate two NGOs' such contributions to social welfare on four principal elements of social capital, e.g. collective action, social trust, coordination and cooperation of mutual benefits, and sharing norms and values argued by Putnam $(1993,2001)$.

\section{Literature Review}

The connotation of the concepts-NGO, social capital, and social welfare - is not well recognised in the literature. NGO is an organisation that is neither a part of a government nor a conventional for-profit business. It is organised on a local, national, or international level. It performs a variety of service and humanitarian functions, brings citizen concerns to governments, advocates and monitors policies, and encourages people to participate in the development activities. NGOs in developing countries such as Bangladesh concentrate to provide services to the disadvantaged people, who are suffering from poverty, unemployment, malnutrition, and natural disasters (Islam and Morgan 2012a). The term social capital has been used so widely that it is very difficult to define it briefly. Social capital has been defined as a variety of different entities consisting of some aspects of social structures and facilitates certain actions of actors within the structure. Social capital is inherently functional, and it is whatever allows people or institutions to act (Coleman 1988). Putnam $(1993,2001)$ stated that social capital is the features of social life networks, norms, and trust that enable participants to act together more effectively to pursue shared objectives. The norms and reciprocal networks make collective action, which are contingent on an existing foundation of social trust and solidarity. Kilpatrick et al. (2001, p. 4) categorised all of the major definitions of social capital into two main groups, e.g. 'collective benefit' and 'individual benefit'. They mentioned that the definitions by Putnam and Narayan and Woolcock (2000) are collective benefit groups and Coleman and Bourdieu's (1986) are individual benefit groups.

Matějů and Vitásková (2006, p. 493) summed up two significantly different approaches to the conceptualisation of social capital. The most dominant stream defined social capital primarily as an attribute of societies and as an inherent characteristic of social environment based on the high degree of interpersonal and institutional trust facilitating people's cooperation. The other stream defined social capital in terms of mutually beneficial exchanges based on social connections and informal networks allowing individuals to achieve their own particular goals. This paper provided both of these streams. The concept 'social welfare' has been used here as an organised function that is regarded as a body of activities designed to enable individuals, families, groups, and communities to cope with the social problems of changing conditions. The literature shows that social welfare has a very loose meaning and means different things in different jurisdictions in the world. Kwok (2003) argued that social welfare has changed substantially in the modern era. Now, beyond the range of its responsibilities for specific services, social welfare has a further function within the broad area of a country's social development. In this larger sense, social welfare plays a major role in contributing to the effective mobilisation and deployment of human and material resources of the country to deal successfully with the social requirements of change, thereby participating in nation building. We used the term 'social welfare' as an organised initiative provided by an organisation (e.g. NGOs) which attempts to provide welfare and services to the individuals, groups, and communities. Here, the scopes of social welfare include NGOs' social well-being; increasing social networks, human skills, social relations, social trust, and income; participatory development; improving local resource mobilisation and development ownership; and community empowerment and community development.

From the above definitions of social capital and social welfare, we can see that there are some areas of NGOs' contributions in social capital development which have multiple impacts on social welfare. A number of studies showed that social capital is used as similar to other social welfare concepts such as community development (e.g. Kay 2005; Islam 2014b, 2012b), community building (Putnam 1993; Potapchuk et al. 1997), community empowerment (Islam and Morgan 2012a, b), and participatory development (Durston 1999). The scope of social capital in terms of the improvement of the quality of relationship among all social networks and its application in a wide range of sectors has given a new meaning and guidance for practice (Kwok 2003). Abom (2004, p. 342) studied that social capital has come to the forefront as a crucial ingredient in achieving equitable and sustainable development, participatory democracy, empowerment from below, and effective government. Bourdieu (1986, pp. 248-249) mentioned that the sources of social capital combined the actual and potential resources, concurrent to tenure of a strong network of more or less institutionalised relationships or reciprocal relationships (e.g. membership). His explanation was concurrently both economic and a set of power relations that comprised a variety of dominions and social interactions generally thought of as non-economic (DeFilippis 2001). Kay (2005, p. 162) showed the relationship between social capital and community development. It is something that exists between individuals and across organisations. In a study of 13 developmental programmes in Asia and Africa, Brown and Ashman (1996) 
found that higher levels of social capital in terms of the number and quality of grassroots organisations, and the degree of inter-sectoral links between public and non-governmental actors, resulted in a more effective programme design, implementation, and significant long-term change. They concluded that the creation and strengthening of social capital is essential to building inter-sectoral collaboration in order to mobilise local resources and direct energies towards future problem solving.

Newton (2001, p. 206) stated that voluntary associations are alleged to create the cross-cutting ties and social networks that bind society together. They create social bonds between like-minded people and bridges between different social groups, wherever there is an overlap. Abom (2004) conducted a study on a low-income urban settlement in Guatemala and found that a wide combination of social, cultural, economic, and political factors was responsible for low levels of broadbased social capital and resultant low levels of collective action and social organisation. Clark (1996) argued that NGOs develop social capital by promoting information sharing, exposing government to neglected grassroots perspectives, and acting as agents of partnership. Jack and Jordan (1999) argued that building social capital in poor communities is a more effective way of promoting children's welfare than the present emphasis on formal child protection and family support services and efforts to increase parenting skills and responsibilities. On the other hand, Uslaner (2002) examined that the overriding message of studies of social capital and welfare state suggests that a decline of trust leads to a decline equality because, in the absence of trust, people are less willing to engage in cooperative relation of the sort required to sustain the welfare state. Social capital includes such structural and psychological elements as the networks of personal relationships and sense of mutual understanding that enable people to live and work together effectively (OECD 2001).

There are a number of recent works that showed NGOs' social capital development initiatives towards social welfare among the vulnerable people in Bangladesh. Buckland's (1998) case study with some prominent NGOs in Bangladesh highlighted how advances made by highly technical income-generation projects came at the expense of community self-reliance and the ability to communicate and promote organisation among the rural poor. Mondal (2000) showed that social capital can be generated by the expectations of the rural poor who are victimised by government and market failures. The demands of the rural poor of Bangladesh for economic and social goods and services, for example, have been instrumental to their economic and social well-being. Cooperation based on mutual trust and norms of reciprocity contributes to the creation of other kinds of capital, especially economic and human capital, that are mutually reinforcing. Dowla (2006) used Putnam's definition in his paper and showed how Grameen Bank (a national NGO) created social capital by forming horizontal and vertical networks, establishing new norms and fostering a new level of social trust to solve the collective action problems of poor people's access to capital. Islam and Morgan (2012b) showed the role of NGOs in term of their capacity as agents of community empowerment in Bangladesh. NGOs' communication and knowledge-sharing practices strengthened linking capacity with outside agents and improved critical awareness among the local producers about their needs. Islam and Morgan (2012a) and Islam (2015) found that NGOs' participatory planning creates routes for social capital; channel of communications helps to improve sharing values, norms, mutual benefits, and collective; and income-generation programmes improved social trust.

\section{NGOs and Community Profile}

We considered Proshika and Practical Action Bangladesh (PAB) for our study. Both NGOs target vulnerable people such as agricultural workers, small farmers, blacksmiths, goldsmiths, pottery and factory workers, micro-entrepreneurs, day labourers, and slum communities. The clients are politically, socially, and physically vulnerable, and face great difficulties in accessing education and human skills and thus in improving their social well-being and quality of life. Proshika is one of the largest NGOs in Bangladesh, which started work in 1975. The main activities of Proshika are human and skills development training, education, employment and income generation, housing, health, and disaster management. The objectives of the Small Economic Enterprise Development (SEED) Programme are to improve vulnerable people's capacity, skills, and use of their local resources towards poverty alleviation. SEED had a number of interventions, e.g. financial assistance (micro-enterprise loans), training, technological assistance, business counselling, marketing extension support, and social education to the entrepreneurs. SEED started work with the goldsmith group at Mirpur-1 Market in January 2004. On the other hand, PAB is an international organisation which provides intermediate technology support to poor people in Bangladesh. Training, social education including information and knowledge sharing, community awareness, and monitoring and supervision are the principal interventions of PAB. It delivers these interventions through building partnerships with governmental institutions and local NGOs. PAB provides training and technological support in a number of areas: food production, agro-processing, small enterprises, and light engineering including fabrication, welding, blacksmithing, and foundry work. The Markets and Livelihoods Programme (MLP) started work with blacksmiths in 2005. The MLP provides skills training, technological support, and advocacy to the blacksmiths. 


\section{Research Question, Objective, Methodology, and Data}

\section{Research Question and Objective}

The principal research question was: What are the contributions of the NGOs' social capital development initiatives such as collective action, social trust, coordination and cooperation of mutual benefits, and sharing norms and values towards social welfare among the blacksmiths and goldsmiths in Bangladesh? The main objective of this study was to justify this question and explore the role of two NGOs on how social capital facilitated towards social welfare. There were two specific objectives to achieve this main objective:

1. To show the capacity of two NGOs on the elements of social capital such as collective action, social trust, coordination and cooperation of mutual benefits, and sharing norms and values.

2. To unearth the contributions of NGOs' social capital initiatives towards social welfare.

\section{Methodology and Data}

\section{Research Approach and Data Collection Methods}

This study was based on qualitative case study approach. It used a multi-method data collection procedure, where a number of data collection methods such as semi-structured interview, social mapping, participant observation, in-depth case study, focus group discussion (FGD), and documentation survey were employed. The multi-method research protocol is especially useful when approaching topics in which intercultural interaction is obscured by phenomena grounded in two or more cultures. The protocol has been articulated for those times when the research questions guiding a particular inquiry may best be addressed by complementary (multiple) methods that are sometimes overlooked in the rush to 'get interviews' (Hoffman 2009). However, we used a multi-method data collection method for two main reasons. First, it is for triangulation which allowed overcoming the limitations of the individual method. Secondly, there were some voices of the community people about the role of NGOs' social capital development initiatives towards social welfare among the vulnerable people which was unable to explore from individual method. The qualitative data collection methods particularly social mapping and participant observation were important to visualise the myriad information about the impacts of social capital towards social welfare among smith communities.
Sampling: Selection of NGOs and Respondents

We selected two NGOs-Proshika and Practical Action Bangladesh (PAB) - and two disadvantaged communities, e.g. blacksmiths and goldsmiths, purposively for this study. We selected these two NGOs because they have a number of years of working experience in the field of social capital development and social welfare for such disadvantaged communities. The Small Economic Enterprise Development (SEED) Programme of Proshika and the Market and Livelihoods Programme (MLP) of PAB were selected for the study which had good relation with the objective of this study. The blacksmith community of Proshika was selected from Mostafapur Bazar at Mostafapur Union in Madaripur District and the goldsmith community of PAB from Mirpur One market at Mirpur, Dhaka District. We found the total 24 shops in Mirpur and 22 in Mostafapur. We considered all of the units of these two NGOs. However, we interviewed all of the heads of those shops who had good experience about the impacts of NGOs' social capital initiatives for social welfare. We conducted five in-depth case studies from each community for gaining detail information. Other respondents were local leaders and NGO staff members at both head and area offices.

\section{Data Collection Instruments and Fieldwork}

We collected data from of the smiths and NGO staff members from both locations through semi-structured interview schedule. There were altogether 46 smiths ( 24 goldsmiths and 22 blacksmiths) and 14 NGO staff members (six from PAB and eight from Proshika) at both head and area offices We included some closed-ended questions (e.g. year of joining with the NGO, income, number of staff members, types of work, types of training received, etc.) and some open-ended questions (e.g. impacts of NGOs' training intervention for increasing human quality, the nature and importance of social networking, importance of knowledge sharing, etc.). We conducted four FGD sessions with the NGO staff members (one with head office and one with area office) and two with community leaders (one in each community). We used social mapping and participant observation methods during the course of 9 months in order to see the outcomes of NGOs' interventions on the elements of social capital towards social welfare. We reviewed relevant literature, which included annual report, office files, and research reports at both NGO offices, and reviewed relevant literature such as books, journal articles, and published and unpublished research reports. Proper data collection instruments were developed, such as separate interview schedule with both structured and unstructured questionnaires for head office and area office staff members, and guidelines for FGD, participant observation, social mapping, and documentation survey. 


\section{Ethical Issues}

The ethical issues are important in conduction social research on human subject in terms of voidance or disclosure of personal conflicts, misconduct and misbehaviour, and perceived objectivity or bias in recruitment and analysis and reporting results. Neither the Social Science Research Council nor any of the NGOs had institutional review boards (IRB), who could approve the study. However, we followed a freestanding IRB. We also followed the ethical guidelines given by Miles and Humberman (1994). A guarantee of confidentiality and anonymity of sources was given to the authorities of Proshika and PAB. We took verbal consent from all participants and the study followed conventional processes in terms of consent, duty of care, and protection of confidentiality in the way the fieldwork was carried out.

\section{Data Analysis Techniques: Triangulation}

Data from interview, FGD, social mapping, participant observation, and in-depth case study transcripts, documentary analysis, and research memos were entered onto an Excel database, to provide structure and flexibility to the management and integration of different types of data (Bazeley 2009). The research questions and conceptual framework had generated an initial start list of analytical codes, which were developed during data analysis. Triangulation permitted the search for convergence and divergence in the multiple sources of information gathered, in order to develop and confirm (or disconfirm) the analytic themes (Creswell 2008).

\section{Results}

\section{Collective Actions}

We asked the NGO staff members, smiths, and local community leaders about the activities of the NGOs that were taken to improve collective actions. We found that NGOs used a number of social networks in this occasion. The NGOs called this 'market/business channel'. All respondents agreed that this network enabled the smiths to enter into a competitive market, where they benefited through collective actions. One SEED staff member mentioned the importance of their programme:

Banks never go to the community; banks do not provide business plan, training, motivational and counselling supports to the community; they don't have social schemes; rather SEED goes to the community and builds up social networks with different sectors.

They built up circles with different community people, community leaders, business partners, wholesalers, designers, and suppliers. They also had an opportunity to justify their existing skills. One blacksmith mentioned:

Nobody comes to see us; I did not see it in my life. Proshika is the only agency who is caring us. My working skills improved a lot after getting skills-training from Proshika. I am now much confident to do quality work; I know all networks in my business from them.

We observed that when a blacksmith entered into a market channel, he needed to know where he got his raw materials (such as coal, iron, steel, and electricity). Then, he needed to build up relationships with the customers, local markets, and suppliers, where he sold his products. Sometimes, he made contacts with a wholesaler, who bought his products and then sold these in the urban markets. The process created two ways of collective actions. The local blacksmiths were able to meet the urban wholesalers in one hand and the wholesalers were able to find the local smiths and bought products at comparatively cheaper prices on the other. This channel created a new 'business route', where the blacksmiths coordinated their traditional skills with the global skills. The whole process was helpful to generate opportunities for gaining social, human, and financial capital. This was also true to the goldsmith.

\section{Social Trust}

We asked a number of questions to the respondents about social trust, e.g. development for whom and who should be developed? Who defines what development is, and why? Whose interest does that definition serve? What kinds of financial and social benefits are being achieved for the smith communities? Who owns the process under which it operates? Due to the high unemployment rate in Bangladesh, we found that NGOs' training facility and loan support directly helped to create 'trust' between NGOs and smiths. One SEED staff member talked about their activities with the goldsmiths:

SEED uses some local languages and techniques to understand the smiths- Who are their debtors? Who are their creditors? How will the creditors get their investments back? Why they are giving them the loan, and what sorts of financial and social benefits will they get and how? How will they pay their loan and how will they improve their savings? SEED is giving a real picture of their calculation how they will sustain their business. These sorts of works help to increase trust between SEED and blacksmiths.

The NGO staff members said that people often trust them more than they did members of their own community. It indicated that families would tell a NGO worker about a problem before telling a friend or neighbour. The smiths and local 
leaders could realise that the NGOs really wanted to improve their livelihoods. One community leader (school teacher) of PAB informed us:

Before implementing their programmes, the staff members of both NGOs visited blacksmiths' houses and explained about the benefits of the participation to their programmes. We saw that the blacksmiths themselves defined their own problems and suggested the solutions from a number of options. In this way, trust was built-up between blacksmiths and PAB, which led to beneficial action through mutual co-operation.

We observed that the NGOs provided income facilities both by recruitment in the organisations and created of income-generation activities in the communities. These had a wide range of impacts on financial, human, and social capital in the society. According to the office data, Proshika had 7138 staff in June 2007. Total primary group members were 2,804, 287; households 2,146,985; poverty free household 1,236, 074; and beneficiaries $11,808,421$. It created 10.51 million employment/self-employment facilities and it had 20.52 million human development training and 1.16 million practical skills development training participants. On the other hand, the PAB's Reducing Vulnerability Programme successfully trained 5265 beneficiaries in 2006, and they claimed that they created a good number of income-generation facilities in Bangladesh.

NGOs' enterprise development enabled the poor beneficiaries to come out of poverty and settled on a sustainable basis. The office data showed that a majority of the beneficiaries expanded their existing business/enterprises ( $71 \%$ ), and more than a quarter of them started new businesses (26\%). Through conducting a survey of 39 entrepreneurs in Dhaka City, SEED reported that after receiving interventions from SEED, the goldsmiths' monthly average income was nearly doubled, and socially, they were in a good position. The smiths and local leaders remarkably mentioned that Proshika had a number of social schemes, which helped to increase social trust. Proshika provided relief and rehabilitation activities during the floods of 1984, 1987, 1988, 1995, 1996, 1998, 2002, 2004, and 2005; the cyclones of 1985, 1991, and 1997; the tornadoes of 1989, 1996, 2005, and 2006; and the monga ${ }^{1}$ of 2005. The floods of 1988 and 1998 and the cyclone of 1991 were colossal and imposed unprecedented damage. During the 1988 flood, Proshika carried out an extensive relief and rehabilitation programme at a cost of Tk. 71.90 million ( $£ 0.65$ million). The relief and rehabilitation programme carried out

\footnotetext{
${ }^{1}$ Monga is seasonal food insecurity in ecologically vulnerable and economically weak parts of north-western Bangladesh, primarily caused by an employment and income deficit before aman (one kind of paddy) is harvested. It mainly affects those rural poor, who have an undiversified income that is directly or indirectly based on agriculture.
}

during the 1998 flood was even more extensive, involving a cost of Tk. 192.30 million (£1.75 million).

\section{Coordination and Cooperation of Mutual Benefits}

In this section, we asked what types of benefits the NGOs offered for the smith communities and how NGOs helped the smiths to create such kinds of mutual benefits. We found that NGOs made efforts for the smiths in order to improve their livelihoods. Both NGOs created interrelation through community survey, community planning, resource allocation, monitoring and supervision with the smiths, community leaders, and local institutions. The objectives of these interventions were to build a social network in order to coordinate and utilise local peoples' efforts. It made a good social bondage among them and with other occupants and people in the community. One blacksmith of PAB said:

That's why we have kept our association's name 'Bhai Bhai (brother) ${ }^{2}$ Karmar Shamity'. We think that our interests and problems are the same. We believe that we can solve many of our problems through discussing them with each other.

Both NGOs followed the 'participatory plan'. This plan was considered as a process framed through consulting a number of groups and validating diverse groups' opinions and needs. This plan gave opportunity to the staff members to explain the reasons and the impacts of participation to the programmes. Both NGOs were somewhat successful in achieving socio-economic improvement, reducing programme costs, and ensuring that needs were met. Along these lines, the smiths found ways to exchange their views or create social networks. These networks increased opportunities for these poor people to improve their ability to work together and provided a safety net for social survival through being part of a group. It was more than just public participation but rather a spectrum of processes, such as involvement, engagement, negotiation, pre-mediation, and mediation. This plan was also a valuable tool for integration between local and other institutions such as the community, Union Parishad (UP) and with the District. This helped to improve peoples' motivation, learning and self-realisation, feelings of ownership, self-esteem, and assessment capacities in order to identify problems and solutions.

\section{Sharing Norms and Values}

We asked about the interventions of the NGOs that they practised in order to share norms and values among the smiths so

\footnotetext{
$\overline{{ }^{2} \text { Here 'brother' }}$ means people who have equal and close relations with each other.
} 
that they could be benefited from these interventions. We found that both NGOs developed channel of communications such as interpersonal contact, business networks, consultations, meetings, training, monitoring, and supervision for sharing norms and values. We can quote a verbatim of the Head of MLP (PAB). He stated:

PAB's every initiative is based on social capital. When we get any concept among a production group, it is not only information, knowledge, or work; we build-up a system which brings visibility of production. For example, if one local producer (smith) wants to know how to make soup, it is possible to impart this knowledge easily via our technical group who transact this technical knowledge to him/her. Then PAB takes the initiative to offer this knowledge in the market through income generation activities.

We observed that both NGOs followed a horizontal type of communication pattern in the office environment, where everybody referred to each other as bhai (brother) and apa (sister) among Muslims or dada/didi ${ }^{3}$ among Hindus, as it was their office decorum. This norm was followed from top to bottom. Both NGO staff members said that they had very good relations with their colleagues and that they were helpful in exchanging information, knowledge, and experiences. The NGOs' group formation was most successful interventions, where the smiths had a chance to develop both human and social capital by observing and practising group rules and principles, values and norms, leadership, and management skills. In addition, both NGOs had face-to-face consultation meetings, where the smiths could share their knowledge and experiences with each other and benefited from this group environment. The staff members generally found these group activities to be dynamic processes for sharing information, updating technologies and improving skills among the smiths. Proshika formed approximately 18,417 Group Federations up to December 2007 all over Bangladesh. These Federations brought people together in cooperation on mutually beneficial projects, thus enhancing communication, reducing objectification of others, and increasing interdependence and trust.

The staff members mentioned that both NGOs had different events for improving collegial relations. For example, PAB held a meeting called shakal shava (morning meeting) before starting their office work, where they openly discussed their office matters. We found this a good practice. Accordingly, SEED had a weekly staff meeting, where they did the same. Their monthly area staff meeting at head office

\footnotetext{
$\overline{{ }^{3} \text { Bhai/apa and }}$ dada/didi translates as brother and sister (with the former referring to a Muslim dialect of Bangla and the latter referring to a Hindu dialect of Bangla) who themselves think that they are equal to each other who hold the same power with their different responsibilities. In one sense, it is a relation where 'power relations' are minimised.
}

was another event, where all area officers shared their observations, thinking, and experiences in terms of what they were able to do, what they could not do, and what they would aim to do in the future. Then, the head of the area officers passed this information to their area office colleagues. We observed that the relationships of shared values were not simply contractual but based on a deeper collective commitment to social change. The meetings and workshops helped to share the concerns, ideas, learning processes, and experiences within the two or groups of employees. These benefited staff members, not only by reducing the gaps but also by improving and developing the employees' level of knowledge, teamwork, attitude, common objectives, values, ownership, participation, and thereby ensuring appropriate conditions to achieve the organisational mission and goals. The frequency of interaction through monitoring and supervision was helpful to generate common social norms ('social glue') and created predictable behaviour. We observed that this process gave a sense of 'belonging' to the organisation, establishing trust among them in helping to develop a stake in organisational goals. The minutes of meetings, periodic activity reports, and reports of such visits across the organisation were maintained in written form. This practice created a constant flow of information throughout the organisation, both vertically, from centre to field and back to the centre, and horizontally, across sub-centres, area and divisional levels. In this way, social capital defined as people's ability to cooperate enhanced economic growth in the communities.

In summary, NGOs' contributions of social capital development towards social welfare were found in the study as follows:

- The norms and values of blacksmiths and goldsmiths were the form of the basis of their social identity, as they earned these distinct characteristics through their daily practices.

- The social interactions and networks provided them the instruments for productive output, which started their skills learning process to product marketing. This process brings social mobility, alliance, social adjustment, and adaptation capacities, and improved their leadership quality.

- The social trust and cooperation offered them an indispensable unity in the social context to ensure that collaborative efforts were integrated in a sustainable way, where social cohesion and harmony were mutually beneficial and important for their ultimate output.

\section{Discussion}

This qualitative study attempted to investigate how NGOs' social capital development practices contributed to social welfare among the blacksmith and goldsmith communities in 
Bangladesh. The main limitation of this study was its subjective validity and lack of comparison with other NGOs as we investigated only two NGOs. However, this finding may not be true with other NGOs working in a similar field. We could not visualise many aspects of how NGOs' social capital development initiatives impacted social welfare among the smith communities. But still we can say that this study pointed out some important aspects. We found that the notion of social capital has been articulated as a concept, which is homogeneous and recognises primarily 'positive' social norms, values, and practices. This study found social capital is the fabric of society. The findings of the study support the argument of Islam (2014a) that the networks trust and shared values of social capital brought human values, knowledge, skills, and expertise of the smiths from their daily communication between and within their neighbours. We found that this network gave many opportunities to both smith communities and NGO practitioners. This is similar to what Mendes and Binns (2013), and Islam (2014a) found in their studies. These appear to be the raw material of communities as Coleman (1988) mentioned. The smiths used their social networks, norms and values, and collective actions through their everyday interactions and contributed to economic and social well-being. These interactions were considered as 'bottomup' phenomena, which were derived from their social connections and networks, such as trust, mutual understanding, and norms of action (Islam 2014a; Islam and Morgan 2012a). We found that, though there were some group conflicts among the local leaders, but their social connections and networks helped to build up a common sense of 'civic' responsibility that integrated them more than a collection of individuals. As a result, both communities improved 'we' feelings attitude and they understood the positive aspect of group interactions. We believe that, without a degree of common identification with the forms of governance, cultural norms, and social rules, it is difficult to imagine a functioning society as mentioned Grootaert (1998) and McClenaham (2000, p. 570).

In network-based resources, social capital was seen as significant in economic development to the smith communities on marketing networks as Malecki and Tootle (1996) found in their studies. External resources, such as loans, training, counselling, monitoring, and supervision were essential for such kinds of small enterprises. However, cooperation was most important to link with one another that the NGO provided to the smith communities. This finding is supported by Robertson and Langlois (1995). We saw that these kinds of enterprises run through cooperation in a number of market channels. Indeed, the constituent elements, such as trust, norms, and networks, that they achieved from their communities were important to maintain their day-to-day life. This finding is supported by Malecki (1998). On the other hand, Buckland (1998, p. 241) asserted that trust, norms, and networks are essential for achieving indigenous efforts at community development. Local social cohesion and mobilisation ensured the vibrancy and success of both local communities and broader state development projects that were viewed as the willingness and capacity to cooperate and engage in collective action for mutual benefit.

The overall findings of this paper can be compared with some other findings, where we can see that NGOs' social capital development initiatives towards social welfare were successful, for examples, NGOs' social networking towards social welfare (Kwok 2003), cross-cutting ties and social welfare (Newton 2001), information sharing and partnership for human welfare among the poor (Buckland 1998), economic and social goods and services for the rural poor (Mondal 2000), NGOs as agents for community empowerment (Islam and Morgan 2012b), and participatory development and community empowerment (Abom 2004; Islam and Morgan 2012a; Islam 2015; Islam et al. 2013). We observed that in some cases, NGOs' social capital initiatives towards social welfare such as social inequalities were problematic. Social inequalities in terms of loan and resource allocation, power relations, social control, and decision making in both communities made difficult to get the benefits of social welfare from social networks. This process clearly reinforced the exclusion that social development activists in disadvantaged smith communities were struggling against those of the groups that were more powerful. Sometimes, social network or relationship pattern was seen more or less linked with interest-gaining processes, which sometimes stopped the natural flow of social relationships. Our finding can be compared with Bayat (2005, p. 10) who stated that the lack of consideration of power as an important shaping feature of social capital might lead to horizontal associations, while neglecting vertical relationship.

\section{Conclusions}

The results of this study have a number of important consequences. The findings of these two case studies are not considered as general proclamation about the entire NGO activities in Bangladesh. But the findings of this study furnished an idea about the role of the NGOs' social capital development initiatives towards social welfare in Bangladesh. The increases of financial, human, and social capital are three significant indicators for the development of disadvantaged smith communities in Bangladesh. In some cases, we observed that the NGOs were facing some limitations to create social capital because of the low level of education of their beneficiaries, poor socio-economical and cultural conditions, noncooperation from community leaders, lack of government initiatives, and NGOs' donor dependency. But in general, we observed that the NGOs' contributions in social capital development was incredible in some areas in social welfare, such as participation of the smiths in the development activities, social 
networking and sharing mutual benefits, collective action, leadership, and income generation. We observed that NGOs' initiatives were convincing in terms of community awareness, increasing problem assessment capacities, encouraging participation, sharing values and norms, introducing new technologies, responding to financial crisis, and mobilising local resources. The findings of this study have wider policy implication in Bangladesh, where most social welfare is being achieved by NGOs. These findings cover a number poverty reduction and social welfare policies in the current long-term plan (sixth 5-year plan 2011-2015) in Bangladesh (Planning Commission 2011). These include income distribution and inequality; participation, social inclusion, and empowerment; and social protection for the disadvantaged communities.

Acknowledgments This paper is based on the author's Ph.D. work completed in the University of Nottingham, England. The author acknowledges his supervisor Professor W. J. Morgan. The author also gratefully acknowledges the generosity of those respondents who participated in the interviews for this study.

\section{References}

Abom, B. (2004). Social capital, NGOs, and development: a Guatemalan case study. Development in Practice, 14(3), 342-353.

Bayat, A. (2005). Defining social capital: a brief overview of the key aspects and debates. Bellville: University of the Western Cape.

Bazeley, P. (2009). Integrating data analyses in mixed methods research. Journal of Mixed Methods Research, 3, 203-207.

Bebbington, A. (2004). NGOs and uneven development: geographies of development intervention. Progress in Human Geography, 28(6), 725-747.

Bourdieu, P. (1986). The forms of capital. In J. G. Richardson (Ed.), Handbook for theory and research for the sociology of education (pp. 241-258). Westport: Greenwood Press.

Brown, D., \& Ashman, D. (1996). Participation, social capital and intersectoral problem-solving: African and Asian cases. World Development, 24(9), 1467-1479.

Buckland, J. (1998). Social capital and sustainability of NGO intermediated development projects in Bangladesh. Community Development Journal, 33(3), 236-248.

Clark, J. (1991). Democratising development: the role of voluntary organizations. West Hartford (UK): Kumarian Press.

Clark, J. (1996). The relationship between state and the voluntary sector. NGO Cafe. February 23, 2014. Available at http://www.gdrc.org/ ngo/state-ngo.html.

Coleman, J. S. (1988). Social capital in the creation of human capital. The American Journal of Sociology, 94(supplementary), 95-120.

Creswell, J. W. (2008). Educational research. planning, conducting, and evaluating quantitative and qualitative research. New Jersey: Pearson Prentice Hall.

DeFilippis, J. (2001). The myth of social capital in community development. Housing Policy Debate, 12(4), 781-806.

Devine, J. (2006). NGOs, politics and grassroots mobilization: evidence from Bangladesh. Journal of South Asian Development, 1(1), 77-101.

Dowla, A. (2006). In credit we trust: building social capital by Grameen Bank in Bangladesh. Journal of Socio-Economics, 35(1), 102-122.

Drabek, A. G. (1987). Development alternative: the challenges for NGOs-an overview of the issues. World Development, 15(Supplement), ix-Xv.
Durston, J. (1999). Building community—social capital. Cepal Review, 69, 103-118.

Farrington, J., \& Bebbington, A. (1993). Reluctant partners? nongovernmental organizations, the state, and sustainable agricultural development. London: Routledge.

Grootaert, C. (1998). Social capital: the missing link. Washington D. C: World Bank.

Hoffman, D. M. (2009) Multiple methods, communicative preferences and incremental interview approach protocol. Forum: Qualitative Social Research, 10(1), Art. 41. August 12, 2014. Available at http://nbn-resolving.de/urn:nbn:de:0114-fqs0901419.

Islam, M. R. (2014a). NGOs' role for social capital and community empowerment in community development: experience from Bangladesh. Asian Social Work and Policy Review, 8(3), 261-274.

Islam, M. R. (2014b). Improving development ownership among the vulnerable people: challenges of NGOs' community empowerment projects in Bangladesh. Asian Social Work and Policy Review, 8(3), 193-209.

Islam, M. R. (2015). Non-governmental organizations and community development in Bangladesh. International Social Work. doi:10. 1177/0020872815574133.

Islam, M. R., \& Morgan, W. J. (2012a). Non-governmental organizations in Bangladesh: their contribution to social capital development and community empowerment. Community Development Journal, 47(3), 369-385.

Islam, M. R., \& Morgan, W. J. (2012b). Agents of community empowerment? The possibilities and limitations of non-governmental organizations in Bangladesh. Journal of Community Positive Practices, 12(4), 703-725.

Islam, M. R., Siti Hajar, A. B., \& Haris, A. W. (2013). Local knowledge in the lips of globalization: uncertainties of community participation in NGO activities. Revista De Cercetare Si Interventie Sociala, 43, $7-23$.

Jack, G., \& Jordan, B. (1999). Social capital and child welfare. Children \& Society, 13(4), 242-256.

Jianxiu, G. (2006). The role of NGOs in social welfare. Canadian Social Science, 2(4), 15-18.

Kay, A. (2005). Social capital, the social economy and community development. Community Development Journal, 41(2), 160-173.

Kilpatrick, S., Field, J., \& Falk, I. (2001). Social capital: an analytical for exploring lifelong learning and community development. Tasmania: University of Tasmania.

Kwok, J. (2003). Social welfare, social capital and social work: personal reflection of a Hong Kong social worker. April 23, 2014. Available at http://www.lwb.gov.hk/download/services/events/040411_wel_ forum/16_joseph_kwok_paper.pdf.

Malecki, E. J. (1998). How development occurs: local knowledge, social capital, and institutional embeddedness. Paper prepared for presentation at the Meeting of the Southern Regional Science Association. Georgia: Savannah.

Malecki, E. J., \& Tootle, D. M. (1996). The role of networks in small firm competitiveness. International Journal of Technology Management, $11,43-57$.

Matějů, P., \& Vitásková, A. (2006). Interpersonal trust and mutually beneficial exchanges: measuring social capital for comparative analyses. Czech Sociological Review, 42(3), 493-516.

McClenaham, P. (2000). Social capital exploring the theoretical foundations of community education. British Educational Research Journal, 26(5), 565-582.

Mendes, P., \& Binns, F. (2013). The integration of community development values, skills and strategies within rural social work practice in Victoria, Australia. Community Development Journal, 48, 605-622.

Miles, M. B., \& Humberman, A. M. (1994). An expanded sourcebook: qualitative data analysis. Thousand Oaks: Sage. 
Mondal, A. H. (2000). Social capital formation: the role of NGO rural development programs in Bangladesh. Policy Sciences, 33(3 \& 4), 459-475.

Narayan, D., \& Woolcock, M. (2000). Social capital: implications for development theory, research and policy. The World Bank Research Observer, 15(2), 225-249.

Newaz, W. (2003) Impact of micro-credit programs of two local NGOs on rural women's lives in Bangladesh, academic dissertation. Finland: the Faculty of Economics and Administration, University of Tampere.

Newton, K. (2001). Trust, social capital, civil society, and democracy. International Political Science Review, 22, 201-214.

Organization for Economic Co-operation and Development (OECD) (2001). Human and social capital are keys to well-being and economic growth. June 28, 2014. Available at http://www.oecd.org/ social/humanandsocialcapitalarekeystowellbeingandeconomicgrowth.htm.

Planning Commission. (2011). Sixth five year plan 2011-2015. Dhaka: Planning Commission.

Potapchuk, W. R., Jarle, P. C., \& William, H. S., Jr. (1997). Building community with social capital: chits and chums or chats with change. National Civic Review, 86(2), 129-140.

Putnam, R. (1993). The prosperous community: social capital and public life. The American Prospect, 4(Spring), 35-42.

Putnam, R. (2001). Social capital: measurement and consequences. Isuma: Canadian Journal of Policy Research, 2(Spring), 41-51.

Robertson, P. L., \& Langlois, R. N. (1995). Innovation, networks, and vertical integration. Research Policy, 24(4), 543-562.

Uslaner, E. M. (2002). The moral foundations of trust. New York: Cambridge University. 